\title{
Analytical group in mild depression - a pilot study of a short- term psychodynamic group intervention.
}

\author{
CRINELA TURCU ${ }^{1}$
}

MIHAELA MINULESCU²

\begin{abstract}
The current study aims at bringing an original contribution to the empirical research body in analytical psychology field, by investigating the impact of a short-term analytical group intervention program on depressive condition. We use at group setting and analytical techniques to promote insights that could reframe the individual's psychological type dynamics leading to decreased depressive symptoms and enhanced emotional balance. The main results obtained from a sample of 20 participants showed significant positive effectson depressive symptoms and neuroticism of our short-time analytical group intervention. Secondary, the impact of the analytical group on psychological type dynamics, extraversion and psychoticism fell short of reaching significant level.
\end{abstract}

\section{Keywords}

Analytical group, psychological types, introversion, extraversion, neuroticism, depressive condition, Singer-Loomis Type Deployment Indicator, Eysenck Personality Questionnaire, young adults.

${ }^{1}$ E-mail: crinela_turcu@yahoo.com.

2 E-mail: mirunaminulescu@gmail.com. 